\title{
China: Estabilidade e crescimento econômico
}

\section{MARCELO JOSÉ BRAGA NONNENBERG*}

\begin{abstract}
China: stability and economic growth. China experienced an extraordinary economic growth since 1978, while keeping inflation low. Which are the main determinants for this performance and to what point has macroeconomic policy been responsible? Obviously, many factors have been important although none of them may be appointed as the sole determinant. The paper also argues whether China would be able to keep this pace of growth or will slow down, like many other Asian countries. It is argued that China will maintain her average rate of growth in the near future.
\end{abstract}

Keywords: China; economic growth; macroeconomic policy; inflation; balance of payments; savings and investment.

JEL Classification: F43; O11; O53.

\section{INTRODUÇÃO}

Não constitui nenhuma novidade o fabuloso desempenho econômico da China desde as reformas iniciadas por Deng Xiaoping em 1978. Neste período, o PIB apresentou um crescimento real médio anual de $10 \%$ - que se compara com uma taxa de 3,7\% para o período 1960-1977 —, ao mesmo tempo em que a inflação, na média, foi de $6 \%$ ao ano. Esse crescimento foi um dos fatores por trás da gigantesca redução da pobreza. Segundo o PNUD, apenas entre 1990 e 2002, o número de chineses com rendimento abaixo de US $\$ 1,00 /$ dia caiu de 490 milhões para 88 milhões. O PIB per capita (PPP) cresceu quase dez vezes entre 1978 e 2004, de acordo com o Center for International Comparisons of Production, Income and

\footnotetext{
* Chefe do IPEA. E-mail: Marcelo.nonnenberg@ipea.gov.br. O autor agradece os comentários e sugestões feitas por Paulo Levy a uma versão anterior do artigo, responsabilizando-se obviamente pelos erros remanescentes. Submetido: Junho 2009; Aprovado: Novembro de 2009.
} 
Prices, da Universidade da Pennsylvania. De acordo com dados do PNUD, o Índice de Desenvolvimento Humano (IDH) da China passou de 0,53 em 1975 para 0,78 em 2006. O grau de urbanização também foi impressionante. A população urbana, que representava cerca de $18 \%$ do total em 1978 , passou a quase $44 \%$ em 2006.

Outros países, ao longo do século XX, também tiveram períodos de forte crescimento econômico e relativa estabilidade de preços. Considerando-se períodos de mais de cinco anos com taxas de crescimento superiores a $6 \%$ anuais em praticamente todos os anos, a partir de 1950, Brasil, Coreia do Sul, Tailândia, Japão, Malásia, Hong Kong e Cingapura tiveram taxas médias de variação do PIB superiores a 7\% a.a. durante esses períodos de crescimento acelerado, de acordo com dados do FMI ${ }^{1}$. Malásia e Hong Kong experimentaram surtos de crescimento de cerca de 30 anos, enquanto Cingapura e Coreia do Sul cresceram aceleradamente durante 40 anos.

O que diferencia a China desses outros países, portanto? Em primeiro lugar, a taxa média anual de crescimento do produto real de quase todos esses países ficou um pouco abaixo da chinesa. Como se observa na Tabela 1 , nenhum outro país cresceu tanto quanto a China entre 1951 e 2007, à exceção de Taiwan ${ }^{2}$ e Cingapura. Entre 1951 e 1977, os quatro Tigres Asiáticos (Taiwan, Hong Kong, Coreia do Sul e Cingapura) e Japão cresceram a taxas anuais entre $7 \%$ e $8 \%$, sendo que Taiwan avançou a um ritmo de $9,4 \%$. Porém, nos 30 anos desde que tiveram início as reformas, nenhum outro país chegou perto do ritmo de crescimento da China. A diferença entre as taxas alcançadas por esses países, entre $6 \%$ e $7 \%$, e a média para a China, de $9,7 \%$ a.a., é bastante considerável em períodos muito longos como esses. Apenas para dar uma ideia, uma taxa de $7 \%$ a.a. durante 30 anos significa que o PIB terá se multiplicado por menos de 8 , ao passo que uma taxa de $10 \%$ a.a. pelo mesmo período, implica multiplicar esse valor por 17.

Em segundo lugar, o tamanho econômico do país. Em 1975, tomando por base as paridades de poder de compra ${ }^{3}$, a economia chinesa era a nona maior do mundo, com um PIB de cerca de 13\% o dos Estados Unidos. Em 2001, segundo esse mesmo critério, já era a segunda maior economia global, representando $46 \%$ da norte-americana em 2006.

\footnotetext{
${ }^{1}$ Dados do IFS; os dados de Taiwan não estão disponíveis.

${ }^{2}$ Infelizmente não há dados para o período mais recente para Taiwan. Porém, se imaginarmos que a taxa de crescimento entre 1978 e 2007 tenha sido semelhante à de Cingapura, no período completo, sua taxa média seria próxima a $8 \%$.

${ }^{3}$ Dados do Penn World Tables para 1975 e Banco Mundial para 2001 e 2006.
} 
Tabela 1

\begin{tabular}{|l|ccc|}
\hline \multicolumn{4}{|c|}{$\begin{array}{c}\text { PAí́SES ASIÁTICOS COM ALTO CRESCIMENTO - 1951-2007 } \\
\text { Taxas Médias de Crescimento Real do PIB (em \%) }\end{array}$} \\
\hline Países & $1951-1977$ & $1978-2007$ & $1951-2007$ \\
\hline China & 4,8 & 9,7 & 7,3 \\
Cingapura & 7,7 & 7,1 & 7,4 \\
Coreia do Sul & 7,3 & 6,5 & 6,9 \\
Hong Kong & 8,0 & 5,7 & 6,8 \\
Tailândia & 6,8 & 5,9 & 6,4 \\
Japão & 7,7 & 2,4 & 4,9 \\
Índia & 3,8 & 5,8 & 4,8 \\
Taiwan & 9,4 & - & - \\
\hline
\end{tabular}

Fontes: IFS/FMI e Maddison (2006); Elaboracão do autor.

O objetivo do presente capítulo é fazer uma análise retrospectiva do desempenho macroeconômico da China nos últimos 30 anos, passando em revista os principais aspectos e traçando as perspectivas de curto prazo. O trabalho está organizado da seguinte forma. A segunda seção apresenta as causas do crescimento econômico da China. $\mathrm{Na}$ terceira seção são apresentados os principais aspectos do seu desempenho macroeconômico, enquanto na última seção são apresentadas as perspectivas.

\section{CAUSAS DO CRESCIMENTO 4}

Quais os fatores responsáveis pelo sucesso da economia chinesa e até que ponto a política macroeconômica colaborou? Obviamente, diversos fatores foram responsáveis por esse crescimento, apesar de nenhum deles, isoladamente, poder ser apontado como o principal. Na verdade, houve uma coincidência de fatores geográficos, históricos, políticos e econômicos, que não podem ser replicados em outros países ou outras ocasiões ainda que a experiência chinesa ofereça lições importantes - que não obstante podem diferir de acordo com a abordagem ao desenvolvimento econômico. Evidentemente, a lista de fatores abaixo tem caráter apenas exploratório, nada se podendo afirmar categoricamente quanto às relações de causalidade, e muito menos quanto ao peso de cada um desses fatores no processo de crescimento. Ainda assim, é bastante razoável imaginar que cada um deles tenha tido uma contribuição relevante para o desempenho da economia chinesa nos últimos 30 anos. Inicialmente, apresentam-se as medidas de política e reformas institucionais que possibilitaram o ciclo de crescimento acelerado. A análise dos aspectos macroeconômicos será feita na seção seguinte.

\footnotetext{
${ }^{4}$ Essa seção é baseada, em boa parte, no Texto para Discussão n. XXX.
} 
Em primeiro lugar, está o processo de liberalização do sistema de formação de preços, que tem início no setor rural, em 1979. Esses preços, que até então, à semelhança dos demais, eram fixados pelo Governo Central, passaram a abrigar um sistema duplo. O Governo Central fixava a cota de produção que cada comunidade (Township and Village Enterprise) deveria entregar a um preço predeterminado. O restante da produção poderia ser negociado livremente no mercado. A partir daí os preços foram sendo liberalizados gradativamente, como será visto na próxima seção. Essa alteração provocou uma grande elevação na produtividade rural, com reflexos sobre a renda e o emprego.

Em segundo lugar, está a liberalização do comércio exterior, uma das primeiras e mais importantes medidas tomadas após 1978. Até então, o comércio exterior era inteiramente planejado pela autoridade central. Além disso, as exportações eram realizadas integralmente por empresas públicas. Como resultado, tanto exportações quanto importações cresciam lentamente. Inicialmente, os controles sobre as importações foram substituídos por elevadas tarifas aduaneiras, reduzidas posteriormente. O sistema de planejamento de importações foi também substituído por barreiras não tarifárias tradicionais, a partir do início da década de 1980. Essas barreiras também foram paulatinamente desmontadas ao longo dos anos. A partir do final da década de 1990, as medidas de liberalização do comércio exterior chinês foram aceleradas com vistas ao seu ingresso na Organização Mundial do Comércio, efetivada em dezembro de 2001.

Em terceiro lugar, a criação de Zonas Econômicas Especiais. A proximidade com Hong Kong inspirou a criação de quatro Zonas Econômicas Especiais (ZEEs), em 1980, em Shenzhen, Zhuhai, Shantou e Xiamen, todas localizadas no litoral sul. Nessas ZEEs, passaram a ser concedidos diversos incentivos, permitindo a criação de clusters, com spillovers positivos. A criação das primeiras ZEEs nessa região permitiu o deslocamento da produção industrial de Hong Kong, sobretudo em setores mais intensivos em mão de obra, cujo crescimento esbarrava em limites físicos, para a República Popular da China, ao mesmo tempo em que HK migrava sua produção para produtos superiores na escala tecnológica. Os bons resultados obtidos nessas áreas levaram o governo chinês a criar, em 1984, outras 14 ZEEs semelhantes, ao longo do litoral. As áreas disponíveis para investimentos estrangeiros expandiram-se rapidamente, atingindo todo o litoral, no final da década de 1980, e alcançando o interior do país na década seguinte.

Quarto, a existência de um grande contingente de mão de obra rural com produtividade muito baixa possibilitou seu deslocamento para as cidades, mantendo baixos os salários, mesmo com crescimento elevado da demanda por trabalho. Entre 1978 e 2006, o número de trabalhadores nas áreas urbanas saltou de 95 milhões para 283 milhões. Ao mesmo tempo, os salários reais médios experimentaram um crescimento anual médio de $11 \%$, muito próximo ao do PIB real. Considerando que, certamente, houve nesse período um forte aumento da produtividade, o custo unitário de trabalho se reduziu.

Em quinto lugar, a ausência de proteção à propriedade intelectual. As EMNs são obrigadas a conviver com um sistema que não garante plenamente a proteção 
da propriedade intelectual. Para ingressar na China, até recentemente, as EMNs necessitavam de um sócio local que costumam se apropriar ilegalmente do conhecimento transferido do exterior para produzir por conta própria, em outra empresa (doméstica), produtos análogos por preços inferiores.

Sexto, o gigantesco tamanho da população da China favoreceu a existência de economias de escala na maior parte das indústrias, com fortes impactos sobre o custo de produção. Alguns exemplos são ilustrativos do tamanho do mercado e da escala de produção. A China é atualmente o maior produtor mundial de televisores, com uma produção anual de aproximadamente 83 milhões de unidades. A produção anual de aço bruto é de cerca de 420 milhões de toneladas, enquanto a do Brasil é de 31 milhões. A China produz atualmente cerca de 1,3 milhão de caminhões por ano, dez vezes a produção brasileira. Enquanto o Brasil produz cerca de 40 milhões de toneladas de cimento por ano, a produção anual da China atinge aproximadamente 1,2 bilhão de toneladas.

Sétimo, o crescimento dos Investimentos Diretos Externos (IDEs). Entre 1981 e 2007, o ingresso de IDE pulou de US\$ 265 milhões para US\$ 138 bilhões. Inicialmente, as empresas multinacionais dirigiram-se quase que exclusivamente às ZEEs - onde receberam diversos incentivos fiscais, terrenos e edificações, além de poderem contar com o benefício de infraestrutura de energia e transporte e da localização ao lado de fornecedores e de outras indústrias semelhantes, bem como de centros de pesquisa, incubadoras de empresas e laboratórios de ponta. Essa localização privilegiada facilitou o surgimento de transbordamentos tecnológicos (spillovers) e teve papel relevante no desenvolvimento tecnológico chinês e na alteração da pauta de exportações ao longo dos últimos 20 anos.

Em oitavo lugar, políticas de incentivo à inovação e à transferência e geração de ciência e tecnologia estiveram intimamente ligadas aos incentivos a investidores estrangeiros. Durante vários anos, a permissão ou o incentivo a empresas estrangeiras esteve condicionado a compromissos no sentido de realização de transferência de tecnologia ou de abertura de centros de P\&D no país. Após o ingresso na OMC, esses compromissos deixaram de ser legais. O agrupamento das indústrias, com spillovers, especialmente das mais intensivas em conhecimento, teve papel relevante no desenvolvimento tecnológico chinês e na alteração da pauta de exportações.

\section{DESEMPENHO MACROECONÔMICO}

Como dito acima, a economia chinesa cresceu a uma taxa real de $10 \%$ a.a. nas três últimas décadas. Entretanto, até 1994, esse comportamento foi marcado por vários ciclos: tanto a taxa de variação real do PIB quanto a de inflação sofreram fortes oscilações, como se observa no Gráfico 1. O crescimento do PIB caiu de cerca de $12 \%$ em 1978 para $5 \%$ em 1981, para atingir $15 \%$ em 1984, retrocedendo para cerca de $4 \%$ entre 1989 e 1990 . A partir de 1991, as taxas aproximam-se cada vez mais da média de $10 \%$. 
Gráfico 1: Taxas de crescimenmto real do PIB e preços ao consumidor - \%

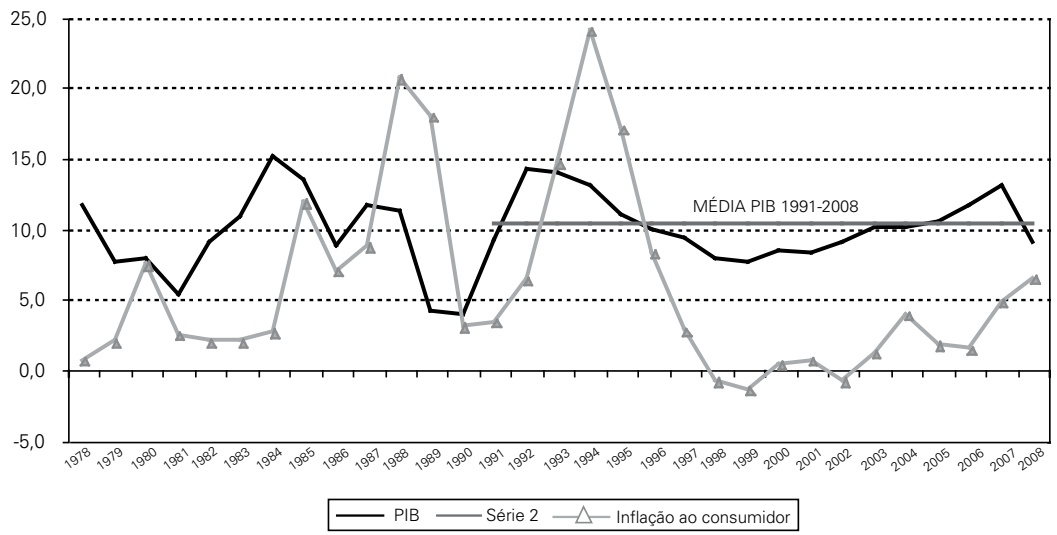

Fonte: NBS, Asian Development Bank e World Bank.

O Gráfico 2 apresenta a contribuição ao crescimento econômico do consumo final, dos investimentos e das exportações líquidas de bens e serviços. Apesar da importância das exportações para a dinâmica da economia chinesa, verifica-se que, ex-post, a contribuição das exportações líquidas é bastante pequena na maior parte do tempo, sendo mesmo negativa em alguns anos, devido ao grande peso das importações. Assim, a quase totalidade do crescimento é explicada pelo consumo e pelos investimentos - embora seja claro que estes últimos foram em boa medida estimulados pela perspectiva de atendimento da demanda externa. Note-se que, nos últimos cinco anos da série, a contribuição dos investimentos suplanta ou iguala a do consumo final, podendo estar havendo um excesso de acumulação de capital. Ademais, na presença de taxas de juros muito baixas, o investimento pode apresentar taxas de retorno muito baixas.

Gráfico 2: Contribuições ao crescimento do PIB - \%

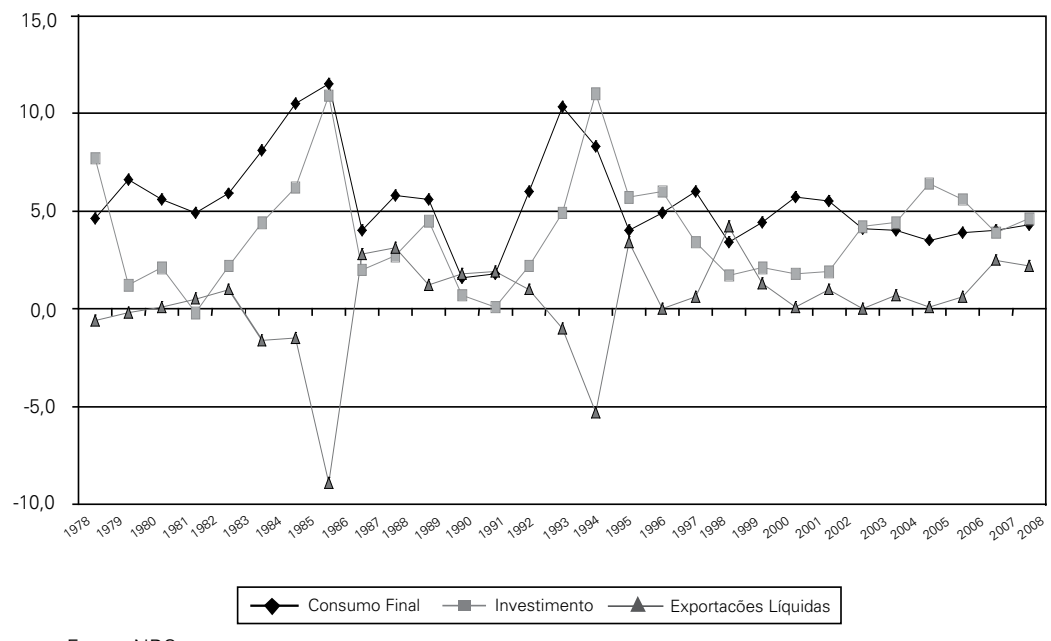

Fonte: NBS 


\section{Inflação}

A inflação oscilou fortemente entre 1978 e 1995, com picos em 1981, 1985, 1988 e 1994, quando chegou a $24 \%$ a.a. Desde então, retrocedeu rapidamente, permanecendo abaixo de 5\% até 2006, para aumentar novamente em 2007 e 2008 . O desvio padrão, que atingiu $7,4 \%$ no primeiro período, caiu para $2,9 \%$ no segundo período.

Normalmente, os ciclos inflacionários dos últimos 30 anos na China são associados a dois fatores básicos. De um lado, o intenso processo de liberalização de preços, de outro, períodos de afrouxamento da política monetária, que permitiram expansão dos investimentos das empresas estatais.

Com relação ao primeiro fator, o processo de liberalização de preços foi bastante intenso entre 1978 e 1992. Em 1978, 97,5\% dos preços de bens vendidos no varejo eram administrados ou "guiados". Esse percentual cai para 55\% em 1988 e 7\% em 1992, caindo lentamente a partir daí. Na verdade, pelo menos até o início da década de 1980, os preços na China eram divididos em quatro categorias ${ }^{5}$ : preços planejados, preços flutuantes, preços negociados e preços de mercado. Os primeiros cobriam a maioria dos preços controlados, sobretudo bens industriais. A segunda categoria foi aplicada durante alguns anos especialmente em bens de consumo, enquanto a terceira categoria permitia alguma flexibilização de preços agrícolas.

A forte ênfase em controle de preços na China entre 1950 e 1980 deveu-se à hiperinflação que assolou a economia chinesa ao longo da década de 1940, antes da Revolução Comunista em 1949. Essa política de controle permitiu, de alguma forma, uma grande estabilidade nos preços entre 1950 e 1978, até ter início o processo de liberalização, à exceção do período entre 1960 e 1962. Mas a hiperinflação ocorrida nos anos 1940 também tornou a cúpula do Partido Comunista Chinês altamente suscetível a episódios de elevação dos preços, levando o governo a adotar políticas bastante austeras toda vez que surgem pressões inflacionárias.

O exemplo mais dramático ocorreu quando os preços se elevaram fortemente em 1988 e 1989. O principal arquiteto das reformas entre 1978 e 1989 havia sido Zhao Ziyang, à época Secretário-Geral do PCC. O clima político mais aberto então vigente permitiu que protestos estudantis, em maio e junho de 1989, em parte motivados pelos aumentos dos preços, assumissem uma dimensão jamais vista, sacudindo a Praça da Paz Celestial, com o resultado conhecido de centenas (ou milhares, dependendo dos relatos) de jovens mortos pelas forças de segurança. Este fato resultou na demissão de Zhao Ziyang e sua substituição por Jiang Zemin e no fortalecimento do grupo liderado pelos principais opositores a Deng Xiaoping, adeptos de maior austeridade fiscal e monetária.

De toda forma, a redução gradual do sistema de controle de preços causou fortes alterações nos preços relativos, contribuindo para a elevação da inflação nos anos acima mencionados. Porém, tais choques somente tiveram impactos mais

${ }^{5}$ Chen e Hou (1983). 
duradouros sobre a inflação por terem sido sancionados, ainda que temporariamente, pelas políticas macroeconômicas.

O Gráfico 3 indica a evolução da relação entre crédito doméstico e moeda, no conceito M1, e o PIB da China, além de mostrar também os episódios de maior aceleração da inflação. Apesar de a inflação não ter ameaçado escapar do controle em 2003 e 2004, ela sofreu uma considerável elevação, passando de $-0,8 \%$ em 2002 para 3,9\% em 2004. Em todos esses momentos, é possível notar que uma aceleração do crédito ou da expansão de moeda precede a aceleração da inflação e é contida em seguida. O fato de os dados serem anuais prejudica parcialmente a análise mas, ainda assim, é possível perceber a relação. De toda forma, percebe-se a preocupação do governo com a aceleração dos preços, não hesitando em adotar medidas restritivas de política monetária sempre que a inflação se acelerou.

Gráfico 3: Crédito e Moeda (M1) como \% do PIB e picos de inflação

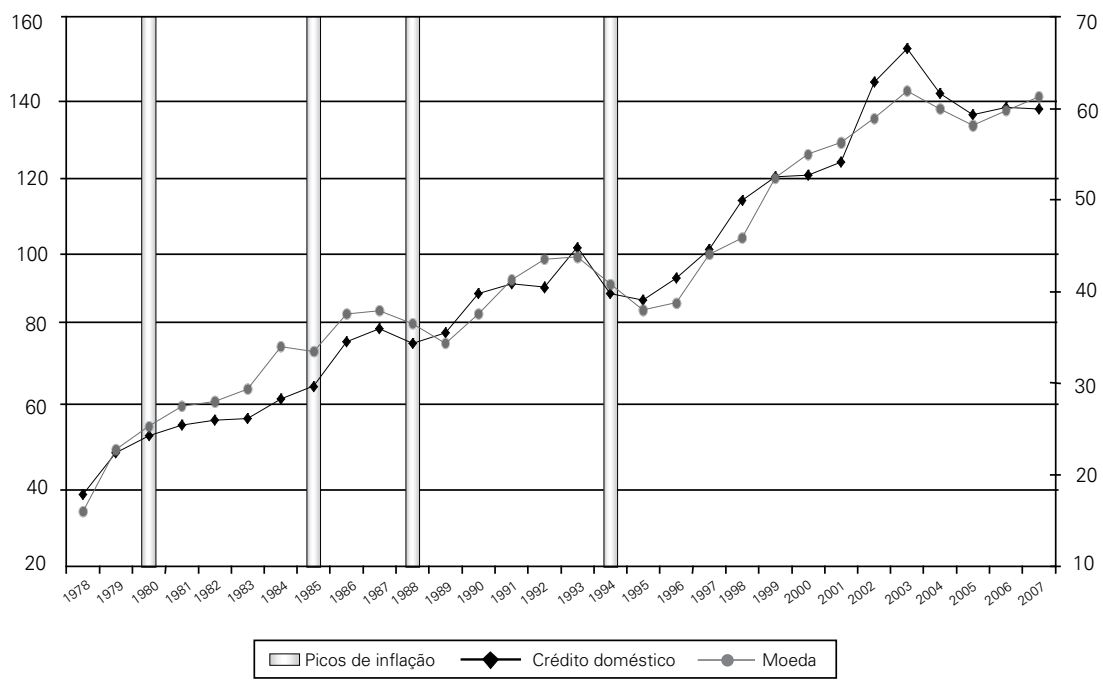

Pode-se também analisar a relação entre inflação e PIB potencial. Uma estimativa simples, porém bastante utilizada para medir o PIB potencial, é por meio do filtro Hodrick-Prescott (HP) para os dados de crescimento real do produto efetivo. No Gráfico 4 são exibidas as taxas de variação real do PIB efetivo e as taxas para o PIB potencial utilizando-se o filtro HP. Verifica-se também aqui que períodos em que o crescimento do PIB efetivo foi maior do que o do PIB potencial precederam elevações da inflação. Essa relação entre aumento da demanda agregada e da inflação na China foi também observada por diversos autores ${ }^{6}$.

\footnotetext{
${ }^{6}$ Ver Gerlach e Peng (2006).
} 
Gráfico 4: PIB - Taxas reais efetivas e potenciais (filtro HP)

e variação dos preços ao consumidor (em\%)

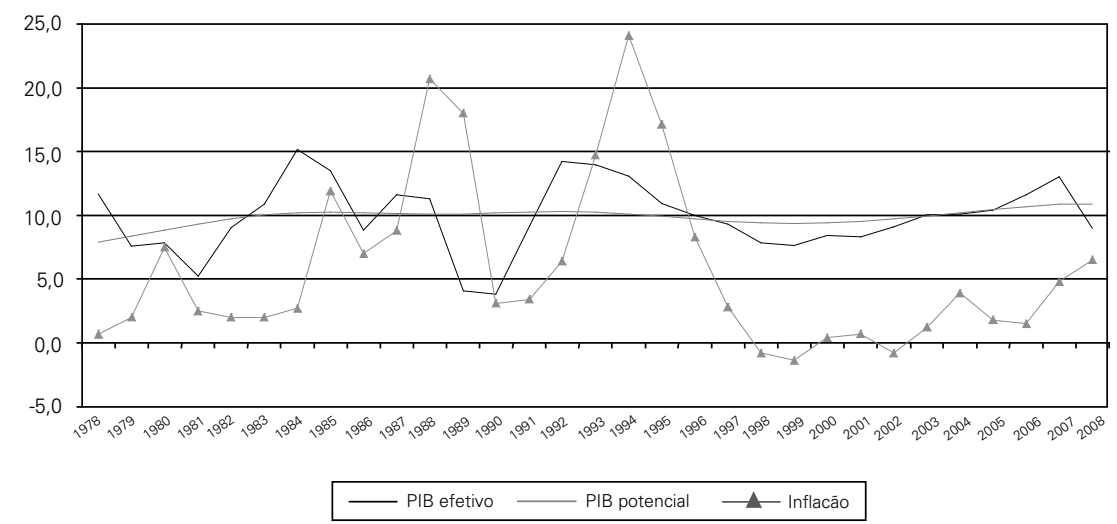

Fonte: NBS: elaboracão do autor.

É razoável considerar, assim, que o período de relativa estabilidade de preços na China entre 1997 e 2006 está fortemente associado ao fato de o PIB efetivo ter crescido a um ritmo muito próximo do PIB potencial, indicando hábil manejo da política de curto prazo. Por outro lado, não há como deixar de se impressionar por um produto potencial crescendo, em média, por quase 30 anos, à taxa de $10 \%$ ao ano.

\section{Comércio Exterior}

Uma das principais características do desenvolvimento econômico da China nos últimos 30 anos foi o expressivo aumento do comércio exterior. Entre 1975 e 2008 , as suas exportações saltaram de US\$ 7,7 bilhões para US\$ 1.428 bilhões, ao mesmo tempo em que as importações pularam de US\$ 7,9 bilhões para US\$1.133 bilhões. Esse extraordinário crescimento foi viabilizado por diversos fatores, sendo os mais importantes a política cambial, especialmente a forte desvalorização real do renminbi ocorrida entre 1990 e 1994, e os ganhos de competitividade da indústria chinesa possibilitada, por sua vez, pela liberalização das importações. No entanto, o comércio exterior somente começa a se tornar peça-chave para o crescimento da economia chinesa no final da década de 1980, quando tanto exportações quanto importações ultrapassam $15 \%$ do PIB.

O Gráfico 5 apresenta as exportações chinesas entre 1983 e 2007 decompostas entre produtos agrícolas, combustíveis e produtos minerais e produtos manufaturados. Percebe-se claramente que praticamente todo o crescimento foi devido à expansão dos manufaturados, em especial material de escritório e de telecomunicações. Esses produtos, que até 1989 representavam menos de $5 \%$ das exportações totais, alcançaram, em 2007, 29\% do total.

No entanto, a China ainda é vista por muitos observadores como um país responsável pela montagem de peças e componentes fabricados em outros países e 
sua transformação em bens de consumo como DVDs, televisores de plasma, computadores e celulares, utilizando sua mão de obra barata e medianamente qualificada. Nesse quadro, as suas importações serviriam, basicamente, como insumos para as etapas finais de produção voltada para a exportação. Portanto, as alterações na taxa de câmbio entre o renminbi e as demais moedas pouco afetaria seu saldo comercial.

Gráfico 5: Exportações por Categorias (US\$ milhões)

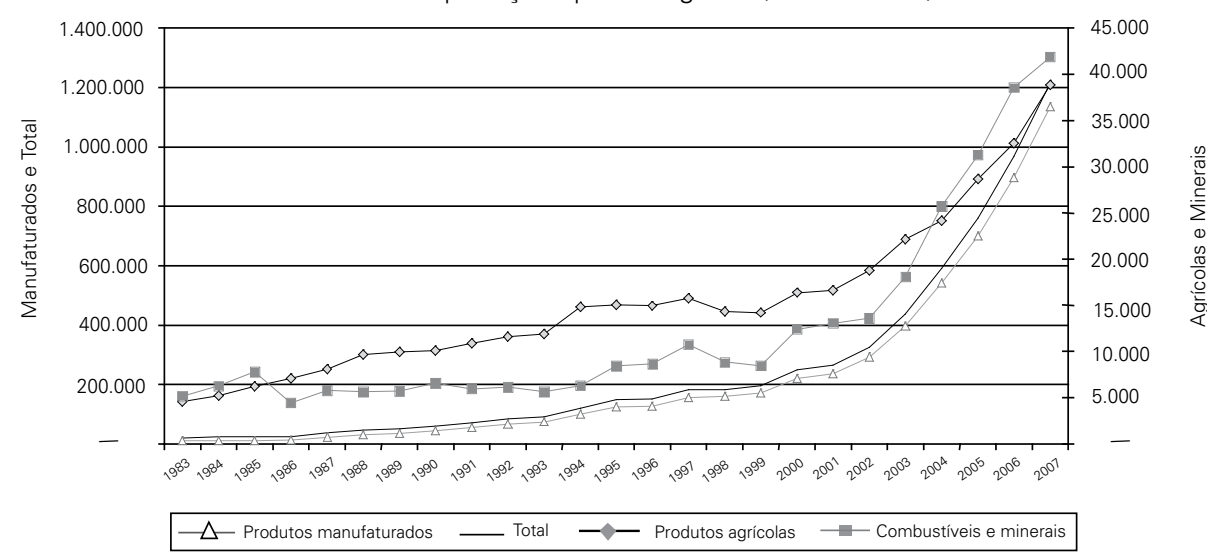

Fonte: WTO

Essa descrição é, até certo ponto, correta com relação à situação prevalecente até alguns anos atrás. Entretanto, muitas mudanças vêm ocorrendo na estrutura produtiva chinesa nos últimos anos, com profundas consequências sobre esse cenário. É preciso lembrar que a China, ao longo das três últimas décadas, vem buscando aumentar sua capacitação tecnológica das formas mais variadas. Ao mesmo tempo, o aumento da produtividade total dos fatores, principalmente a partir da década de 1990, mesmo que em ritmo declinante, vem sendo um dos principais responsáveis pelo extraordinário crescimento econômico da China.

Tudo isso contribuiu para uma alteração na estrutura produtiva, que vem possibilitando o avanço da indústria chinesa ao longo da cadeia de valor, aumentando cada vez mais o valor agregado e o conteúdo tecnológico de suas exportações.

Dessa forma, não apenas o superávit comercial total vem aumentando ano a ano, mas o superávit em produtos de alta tecnologia também vem crescendo nos anos recentes, sobretudo em material de escritório e informática e equipamentos de rádio, TV e comunicação.

As importações da China, por sua vez, passaram a apresentar um comportamento explosivo a partir de 1999, também devido à forte elevação dos produtos manufaturados, como se observa no Gráfico 6. Destacam-se, em primeiro lugar, equipamentos de rádio, TV e comunicação, seguidos por material de escritório e informática, produtos químicos, exclusive farmacêuticos, máquinas e equipamentos 
mecânicos e produtos siderúrgicos e metálicos. Isso é mais uma indicação de que cresceram não apenas as importações de partes e peças de equipamentos eletrônicos como também os bens de capital e as matérias-primas para produzi-los, aumentando o valor agregado na China.

Porém, é também possível observar no mesmo gráfico o enorme crescimento das importações de combustíveis e minerais desde 2003. Esse aumento se divide em partes iguais entre combustíveis, de um lado, e produtos minerais, de outro. Uma das razões para esse aumento foi o crescente déficit de fontes de energia da China, sobretudo petróleo. Entre 1991 e 2006, enquanto a produção de energia, em todas as fontes, cresceu a 4,8\% ao ano, o consumo cresceu a 5,9\%. As importações de petróleo, que representavam apenas 6,6\% do consumo em 1990, saltaram para $43,1 \%$ em 2000 e 55,8\% em 2006. Com isso, a demanda de petróleo da China, que representava $5,6 \%$ da demanda global em 1999 , pulou para $8,8 \%$ em 2007 , constituindo parcela expressiva do aumento da demanda global de produto no período recente. Apesar de a China ser o maior produtor mundial de minério de ferro ${ }^{7}$, a demanda vem crescendo a um ritmo superior ao da oferta nos últimos anos, causando um forte aumento das suas importações.

Gráfico 6: Importações por categorias (US\$ milhões)

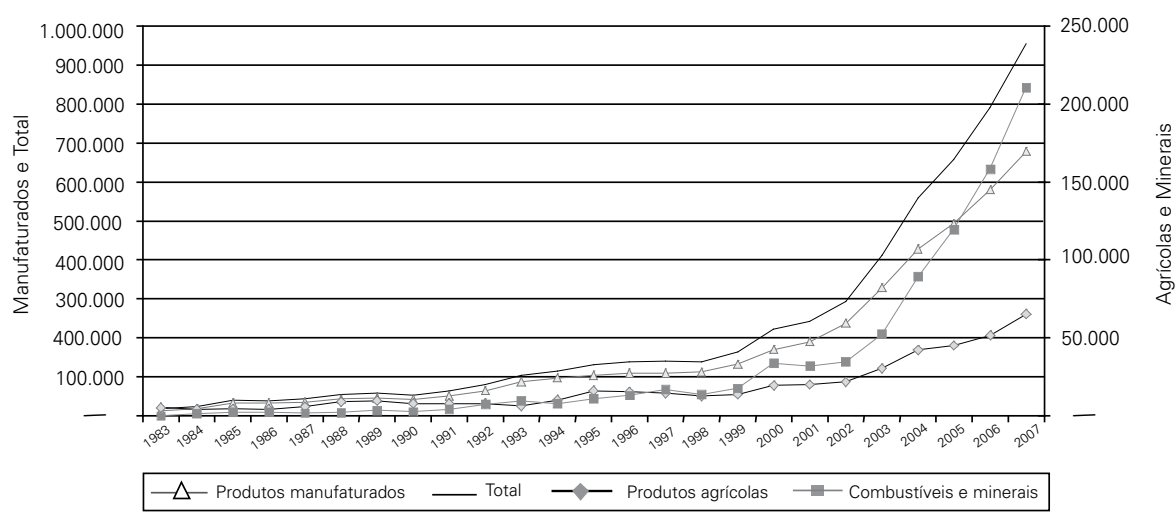

Fonte: WTO.

Como mencionado na seção anterior, a política comercial da China foi bastante alterada nos últimos 30 anos. Até 1978, tanto as importações como as exportações de bens eram totalmente controladas pelo governo central. Portanto, nem preços nem a taxa de câmbio exerciam qualquer papel na determinação dos fluxos $^{8}$. Mesmo nos primeiros anos após o início das reformas em 1978, persistia um sistema altamente complexo de regulações do comércio exterior. A partir do início da década de 1980, várias reformas foram introduzidas, reduzindo a força

\footnotetext{
${ }^{7}$ Em peso bruto de minério; em termos de conteúdo de ferro, o Brasil é o maior produtor.

${ }^{8}$ Ver Lardy (2002), cap. 2.
} 
dos mecanismos de planejamento e de regulação quantitativa e, ao mesmo tempo, elevando fortemente as tarifas de importação, que passaram a substituir os antigos controles.

Em 1985, foi feita uma nova reforma do sistema de tarifas, que reduziu a tarifa média de $55,6 \%$ para $43,3 \%$. A partir de 1992 , teve início novo processo de redução de tarifas, que levou a tarifa média a cair para 15,3\% em 2001, às vésperas do ingresso na Organização Mundial de Comércio, em dezembro desse ano. Já em 2005, a tarifa média havia caído ainda mais, para 9,7\%. Ao mesmo tempo, as barreiras não tarifárias foram paulatinamente reduzidas, simplificando-se o regime de licenciamento e eliminando-se a maioria das proibições e restrições à importação. Nos anos recentes foram também realizados alguns acordos comerciais com países asiáticos, concedendo tarifas preferenciais, especialmente a Hong Kong.

Portanto, o crescimento das importações foi, em grande parte, incentivado pelas reformas da política comercial e explica por que esse aumento foi tão forte mesmo na presença de uma taxa de câmbio subvalorizada.

\section{Balanço de Pagamentos}

O enorme crescimento das exportações a partir de 2001 resultou num contínuo crescimento dos saldos externos da China. Como se verifica no Gráfico 7, o saldo em conta corrente, que se situava pouco acima de US\$ 1 bilhão entre $1982 \mathrm{e}$ 1996, passou para cerca de US\$ 27 bilhões entre 1997 e 2002, aumentando exponencialmente a partir daí para alcançar US\$ 372 bilhões em 2007. O resultado global do balanço de pagamentos, por sua vez, alcançou resultados semelhantes nos mesmos períodos, para registrar US\$ 462 bilhões em 2007 (US\$ 600 bilhões em 2008, de acordo com dados preliminares). Dessa forma, as suas reservas internacionais, que eram inferiores a US\$ 150 bilhões até 1998 , saltaram para US\$ 2 trilhões no final de 2008.

Como foi possível à China acumular reservas internacionais em valores tão elevados, mantendo a taxa de câmbio fixa sem, ao mesmo tempo, gerar pressões inflacionárias? A contrapartida da elevação das reservas é o aumento da dívida pública. Quanto maior a dívida, maiores os encargos financeiros e maior o déficit fiscal. Entretanto, à diferença da maior parte dos demais países, tanto o déficit fiscal da China quanto o valor inicial da dívida pública eram relativamente pequenos. A dívida bruta do governo central passou de aproximadamente $6,5 \%$ do PIB em $1990^{9}$ para $15,7 \%$ em $2008^{10}$.

\footnotetext{
${ }^{9}$ De acordo com o Banco Mundial.

${ }^{10}$ Segundo o CIA World Factbook.
} 
Gráfico 7: Balanço de pagamentos — Principais rubricas em US\$ milhões

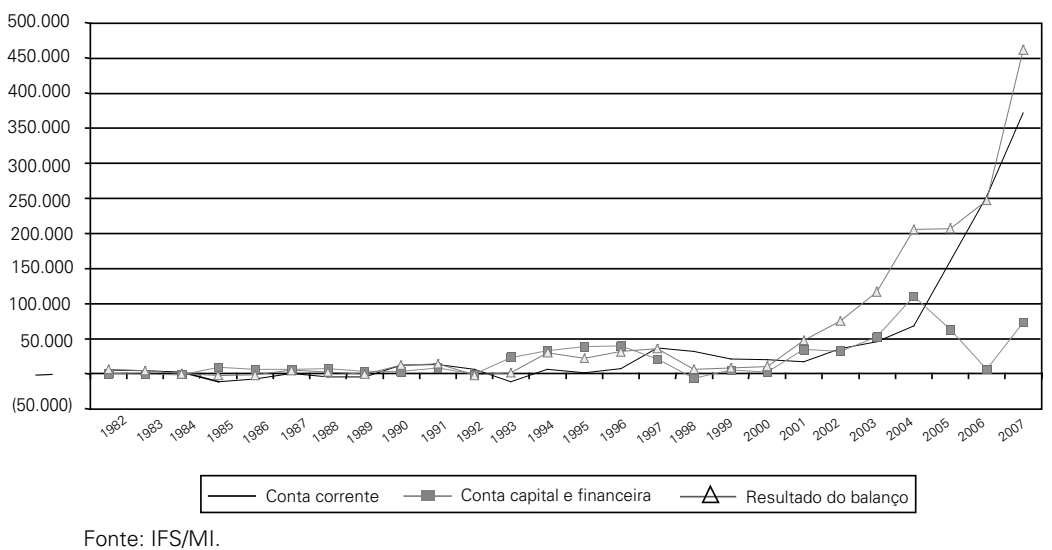

Como também é possível observar pelo Gráfico 7, os fluxos externos de capital eram bastante reduzidos até 1992. A partir de 1993, passam a crescer rapidamente, basicamente em virtude da expansão dos ingressos de investimentos diretos externos (IDE). Em 1972, após a visita do presidente Nixon à China, os IDEs foram formalmente liberados na China, porém sua magnitude continuou inexpressiva por vários anos. Após 1979 foi promulgada uma Lei de Joint Ventures ${ }^{11}$ que começou a, de fato, permitir o ingresso de empresas multinacionais (EMN). Mas o principal passo foi a criação das Zonas Econômicas Especiais em 1980, que forneciam incentivos à instalação de EMN, seguidas por outras 14 em 1984. Porém, o ingresso de IDE só começou a crescer, de fato, a partir de 1992, tendo recebido maiores incentivos desde o ingresso da China na OMC, tendo a China se tornado o principal recipiente mundial de investimentos externos.

Até 1995 , cerca de $60 \%$ dos IDE eram originários de Hong Kong, com participação ainda discreta do Japão, Taiwan, Estados Unidos e União Europeia. Na presente década, a participação de Hong Kong caiu para cerca de $30 \%$, ao passo que a estrutura de origem se diversificou substancialmente. A participação dos demais países da Ásia alcança atualmente cerca de $28 \%$.

O extraordinário aumento dos superávits em balanço de pagamentos da China a partir de 2002 vem sendo apontado por diversos analistas como um das causas principais do desequilíbrio global. Ao longo da presente década, os déficits em conta corrente dos Estados Unidos cresceram velozmente, porém, até 2004, puderam ser compensados em grande escala pelos superávits correntes dos demais países avançados (aí incluídos os chamados Tigres Asiáticos). No entanto, desde então, passaram a representar, em grande medida, a contrapartida dos superávits chineses.

É importante perceber que foram os superávits chineses que permitiram o

${ }^{11}$ Ver Branstetter e Feenstra (1999). 
crescimento dos déficits norte-americanos. Isso porque o excesso de poupança na Ásia resultou numa redução das taxas de juros globais, que contribuíram para a expansão do consumo (e do investimento) nos Estados Unidos que, por sua vez, acarretou o aumento do déficit em conta corrente. Dito de outra forma, o excesso de poupança (sobre os investimentos) da China financiou o excesso de consumo nos Estados Unidos. Essa questão é analisada mais detidamente no item a seguir.

\section{Poupança e Investimento}

O Gráfico 8 evidencia a participação da poupança e do investimento sobre o PIB, sendo possível distinguir claramente três períodos. O primeiro vai de 1978 a 1992 , com ambos os valores oscilando entre valores pouco superiores a $35 \%$ do PIB. No segundo, de 1993 a 2000, os valores se elevam pouco acima de $40 \%$ para diminuir nos anos seguintes, mas mantendo o equilíbrio. A partir de 2001, ambas as taxas aumentam aceleradamente, porém se distanciando cada vez mais, com a poupança atingindo impressionantes $54 \%$ em 2007 , ao passo que os investimentos estacionam em torno de $43 \%$, ainda assim uma cifra muito elevada.

Gráfico 8: China: Poupança doméstico e investimento como \% do PIB

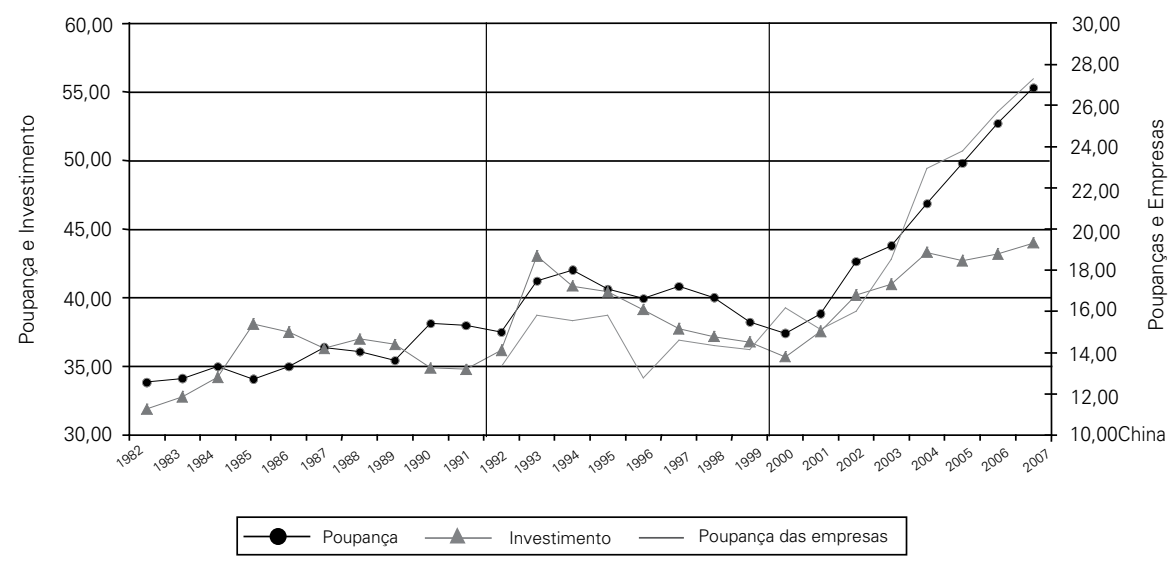

Deve-se, então, indagar quais as razões pelas quais a taxa de poupança na China é tão elevada. Tanto o setor público quanto as famílias e as empresas apresentam poupanças líquidas positivas. A poupança das famílias vem se mantendo, de acordo com estimativas, em torno de $17 \%$ do PIB, ao mesmo tempo em que a poupança das empresas deve ter passado de cerca de $15 \%$ do PIB no início da presente década para próximo a $27 \%$ em $2007^{12}$.

As famílias poupam muito porque necessitam cobrir a maior parte dos gastos

\footnotetext{
${ }^{12}$ As contas nacionais chinesas não permitem essa desagregação. Esses números refletem uma média de estimativas realizadas pelo Banco Mundial e pela OECD.
} 
com saúde, educação e previdência, uma vez que o governo cobra por esses serviços, ainda que parcela expressiva da população receba alguns subsídios para saúde e educação. As empresas, boa parte delas de propriedade do Estado, auferem lucros muito elevados, em razão do forte crescimento da atividade e de custos relativamente baixos. Não apenas os salários são baixos, mas diversos serviços públicos como energia, transporte e saneamento são subsidiados pelo Estado, principalmente nas ZEEs. Além disso, os empréstimos são concedidos a taxas de juros bastante reduzidas, mesmo a empresas com riscos elevados. A forte participação da indústria também é um elemento importante nessa equação. As empresas industriais apresentam uma participação de investimentos maior do que a dos demais setores da economia e necessitam de maiores lucros retidos. Finalmente, o Estado obtém taxas de poupança mais elevadas do que a média dos demais países pois seus gastos em saúde, educação e previdência são bem menores do que os da maior parte dos demais. Alguns estudos mostram também que a evolução demográfica na China apresenta um efeito positivo sobre a poupança, na medida em que a parcela de população em idade adulta (maiores poupadores) é relativamente alta.

Pode-se especular sobre as razões para o crescente distanciamento entre poupança e investimento. A poupança, desde 2002, cresceu principalmente devido à elevação da poupança das empresas. Isso, por sua vez, deve-se à combinação de três fatores ${ }^{13}$ : em primeiro lugar, o grande aumento da lucratividade das empresas nos anos recentes. Segundo, à política de distribuição de dividendos: enquanto os acionistas privados recebem poucos dividendos, o Estado, acionista majoritário, praticamente não os recebe. Em terceiro lugar, boa parte do crescimento econômico da China foi devido à acumulação de capital, estimulando as empresas a reterem parcela substancial dos lucros. Mas não se pode deixar de lado que a poupança do governo também vem crescendo como proporção do PIB.

Os investimentos, por sua vez, sendo realizados principalmente pelas empresas, não podem crescer na mesma proporção, pois são limitados pela rentabilidade esperada dos novos projetos.

Assim, é extremamente difícil a China continuar crescendo com base em tão forte dependência dos investimentos. $\mathrm{O}$ aumento da capacidade produtiva tem que ser absorvido pela expansão das exportações ou do consumo, caso contrário a ociosidade irá aumentando cada vez mais, reduzindo acentuadamente a rentabilidade de novos investimentos, o que poderia provocar uma redução abrupta do processo de crescimento. Não se pode perder de vista o fato de que, apesar da grande participação de empresas estatais na economia, a China funciona com base nas leis do mercado.

As taxas de poupança e de investimento na China são muito mais altas do que a da grande parte dos países. O Gráfico 9 mostra os dados de poupança doméstica e formação bruta de capital fixo (FBCF) como proporção do PIB para uma amostra de 152 economias, entre as maiores, para 2005, segundo dados do Banco Mun-

\footnotetext{
${ }^{13}$ Ver Kuijs (2006).
} 
dial. A maior parte dos países apresenta taxas de poupança doméstica entre $-5 \%$ e $45 \%$, com a FBCF variando entre $10 \%$ e $30 \%$. Enquanto isso, a China apresentou poupança doméstica de $49 \%$ e investimento de $42 \%$.

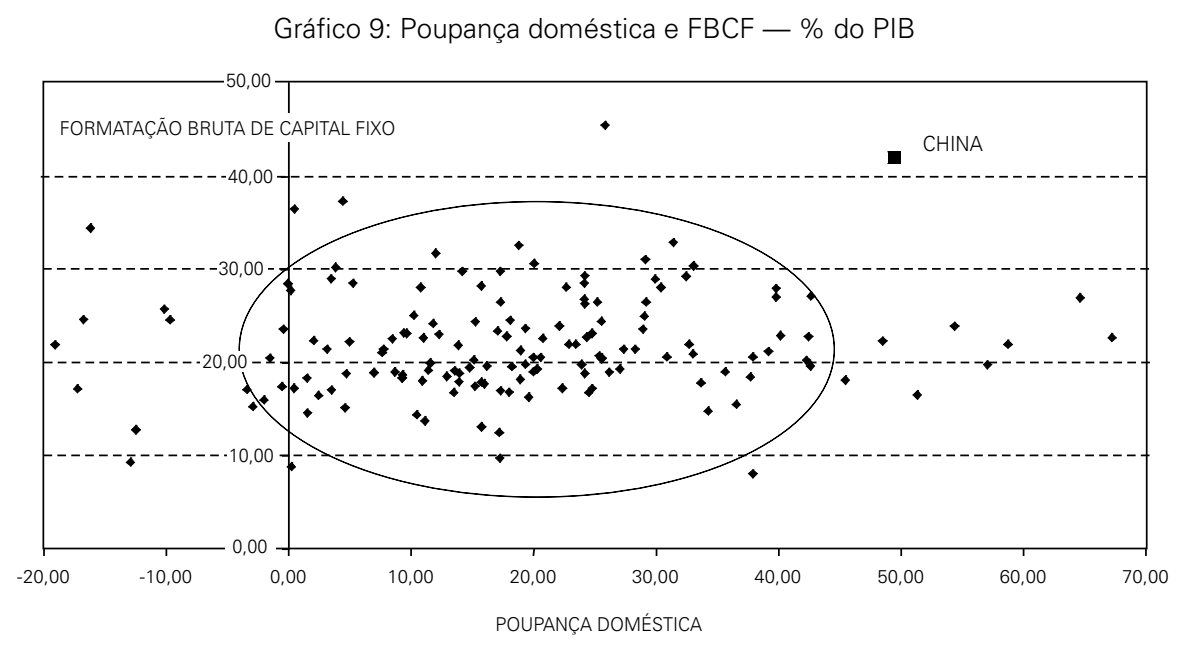

\section{PERSPECTIVAS}

Buscou-se, neste capítulo, passar em revista os principais aspectos recentes da economia chinesa, após o início das reformas em 1978. Mais especificamente, o foco foi dirigido às questões macroeconômicas, com ênfase nas questões do crescimento, inflação, balanço de pagamentos e poupança e investimento. Falta, portanto, esboçar uma análise das perspectivas da economia chinesa para os próximos anos e dos seus principais problemas.

A principal pergunta é: será que a China continuará a crescer a um ritmo semelhante ao que experimentou nos últimos 30 anos ou ela irá passar em breve por uma forte desaceleração, a exemplo do que já aconteceu com Japão, Coreia do Sul e Hong Kong? De acordo com a mais recente projeção do FMI ${ }^{14}$, após crescer a $8 \%$ em 2009, a China verá seu PIB se elevar a 7,5\% em 2010 e 10\% em 2014. Já a OCDE prevê que a taxa de crescimento irá subir de 5,9\% em 2009 para 7,2\% em 2010.

De fato, é bastante provável que a China possa ainda, por vários anos, manter um vigoroso ritmo de crescimento, bastante próximo à média observada nas três últimas décadas.

Vários fatores concorrem para isso. Em primeiro lugar, como foi visto, o crescimento da China deveu-se, em grande parte, ao aumento dos gastos em investimentos. É razoável imaginar, portanto, que a indústria e os serviços possuam gran-

\footnotetext{
${ }^{14}$ World Economic Outlook, I, 2009.
} 
de capacidade ociosa, ainda que boa parte dos investimentos públicos recentes tenham sido realizados em obras de construção civil.

Em segundo lugar está a questão da poupança. O fato de a taxa de poupança na China ser extremamente elevada, inclusive superior à de investimentos, significa que há muito espaço para que o crescimento possa ser incentivado por meio de maiores gastos em consumo. Essa, aliás, é não apenas a prescrição de praticamente todos os analistas da economia chinesa, como também é um objetivo declarado do governo. Políticas voltadas para ampliação dos gastos públicos em saúde, educação e previdência social terão como resultado reduzir a poupança do setor público e das famílias, elevando o consumo final.

Em terceiro lugar, o fato de os gastos em P\&D serem cada vez maiores assegura à China a capacidade de manter seu potencial inovador, fonte importante para o crescimento. Alia-se a isso um elevado número de pessoas com educação superior, em especial nas áreas científicas e tecnológicas.

A segunda pergunta mais importante refere-se à evolução do balanço de pagamentos e de suas principais contas e, consequentemente, da acumulação de reservas internacionais. Conforme foi visto, as exportações da China cresceram principalmente devido a produtos relativamente intensivos em tecnologia, que estão entre os mais dinâmicos no comércio internacional. Como a China está investindo cada vez mais em inovação, o que aumenta sua competitividade, é altamente provável que suas exportações possam continuar crescendo por mais alguns anos a um ritmo parecido com o observado, ainda que haja alguma desaceleração em 2009 e 2010. Outro fator que irá colaborar para esse crescimento é o recente esforço da China em desenvolver marcas próprias, aspecto fundamental em setores como, por exemplo, informática e automobilística.

Já as importações, caso o cenário de ampliação do consumo se confirme, deverão crescer a uma velocidade um pouco maior, reduzindo dessa forma o superávit comercial e o superávit em conta corrente, ainda mais que a parcela de bens de consumo importados ainda é relativamente pequena.

Um outro aspecto refere-se ao papel do renminbi nas finanças internacionais. A China vem se mostrando cada vez mais interessada em ampliar o papel da sua moeda no cenário internacional. Recentemente, o presidente do Banco Central da China lançou a ideia de que o dólar deixe de ser a moeda de reserva internacional para ser substituído por outra moeda, dissociada de países individuais, e que possa permanecer estável a longo prazo. Para alcançar esse objetivo, é preciso aumentar ainda mais a circulação da moeda chinesa na economia global. Portanto, seria necessário que a China ampliasse a liberalização da sua conta capital, estimulando os investimentos chineses no exterior, tanto sob a forma de investimentos diretos como investimentos em carteira. É bem verdade que a participação da China no comércio internacional é cada vez maior, alcançando, em 2008, cerca de $8 \%$ dos fluxos totais, que se compara com $11 \%$ dos Estados Unidos.

Em suma, a China deverá ter um papel cada vez mais relevante no cenário econômico global, aumentando sua participação no PIB mundial, no comércio internacional e nas finanças globais. A contrapartida desse processo será a amplia- 
ção do peso da China também no cenário geopolítico internacional o que acarretará em maior complexidade das relações internacionais. O mundo após o término da Guerra Fria caracterizou-se por uma hegemonia quase inconteste dos Estados Unidos, havendo quem caracterize o quadro político internacional como sendo unipolar.

Os dois outros grandes atores - Japão e União Europeia - fazem parte do mesmo bloco há mais de 50 anos e nunca representaram ameaça de contestação à liderança norte-americana em questões relevantes.

A China, por sua vez, apresenta objetivos próprios e alguns interesses divergentes. Há uma expressão antiga, ainda da dinastia Qing, no século XIX, que ainda inspira os dirigentes chineses: país próspero com um exército forte (fuguo qiangbing). Não é segredo que a China ambiciona criar um espaço hegemônico na Ásia e, para isso, não tem hesitado em ampliar seus gastos militares, que já representam mais de $10 \%$ do orçamento. Dessa forma, à medida que esse país aumenta seu peso na economia mundial, o potencial de conflitos também cresce.

\section{REFERÊNCIAS BIBLIOGRÁFICAS}

BRANSTETTER, L.; FEENSTRA, R. Trade and Foreign Investment in China: A Political Economy Approach. Disponível em: <http://papers.ssrn.com/sol3/papers.cfm?abstract_id=164968>

CIA. The World Factbook. Disponível em: <https://www.cia.gov/library/publications/the-world-factbook>

CHEN, N.; HOU, C. China's Inflation, 1979-1983: Measurement and Analysis. University of Chicago, 1986

FMI. International Financial Statistics. Disponível em <http://www.ifsworld.com>

FMI. World Economic Outlook , I, 2009, Washington

GERLACH, S.; PENG, W. Output gaps and inflation in Mainland China Bank of International Settlements, February 2006 (BIS Working Papers n 194)

KUIJS, L. How will China's saving-investment balance evolve? World Bank China, Office Research, July 2006.

LARDY, N. Integrating China into the global economy. Washington: Brookings Institution Press, 2002

NONNENBERG, M.; LEVY, P.; NEGRI, F.; COSTA, K. "O Crescimento Econômico e a competitividade chinesa”. Instituto de Pesquisa Econômica Aplicada, Abril 2009 (Texto para Discussão $\left.\mathrm{n}^{\circ} 1333\right)$

Penn World Tables. Disponível em : <http://pwt.econ.upenn.edu> 